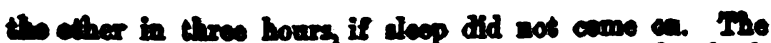
net das, Doc. I1, I found she had slopt, having taken both dianghta. Sthe was better. Pulve 100. Had falso imprescions, and expreseed great dislite to her nurse. Repeated the morphis, one grain morning, and one at night. Dec. 22. Better. Doc. 23. Nearly well." (Note in Register.)

There was something of an intermittent character about this case: the maniacal symptoms prevailing at night, and coesing in the day.

RrXuRKs. On comparing all these cases together, I think I am fully justified in repeating the question-By what signs or circumstances are we to measure the amount of danger in a case of puerperal mania? Let us take frequency of pellse, which most writers are agreed in looking upon as a guide in prognosis, and we shall find that, in the first case here reported, the pulse might be said to be natural throughout, any occasional acceleration being obviously due to excitement only; while in the case of the patient who had the disease three times, the pulse was more frequent in the second attack, from which she recovered, than in the third, of which she died.* Suppression of the milk is another important symptom; so important, that it was formerly looked upon as the cause of this kind of mania, the disease having been hence named "maria lactea". But in the first case here reported, although the milk was late in appearing, and was then scanty in quantity (circumstances perhaps accounted for by the hæmorrhage), yet the disease did not show itself until the secretion had been in some sort established for several days. That it was gradually suppressed in the course of the disease, was not to be wondered at. Then, again, with the patient who suffered from three attacks, the milk gradually disappeared in the second attack, from which she recorered, and never returned; while in the third attack, of which she died, the milk was not suppressed until the fifth day of the disease, and actually reappeared in the breasts a day or two before the fatal termination. In the second case reported in this paper, the milk was abundant for several days after the disease had appeared, and was not quite suppressed when the patient died. So that the presence or absence of the milk can hardly indicate anything whatever.t It may be said that we may find indications of danger in other circumstances, if we only watch for them; and such a circumstance was actually present in the last reported case, in which, the disease having commenced as early as the fifth day, and being attended with a quick pulse, the patient had during her pregnancy suffered from occasional pain in the head, with partial blindness of one eye, symptoms very likely to depend on mischief in the brain itself; but this patient recovered quicker than any of them.

As for the causes of puerperal mania, I think it quite clear that any peculiar circumstances connected with the labour itself can have nothing whatever to do with the production of the disease. I have been somewhat minute in these reports, for the purpose of showing this: the attacks of mania following equally, whether the labour was hard or easy, complicated or uncomplicated; these differences being observable even in the same patient. The attack of hæmorrhage which complicated or followed the labour in the first case reported, may indeed have unduly depressed the system, so that want of sleep and want of food might more

* Speaking of the progncsis in puerperal mania, Dr. Ramsbotham observes:- "The sooner after delivery the attack occurs-the quicker the pulse again:- "If I were to select any single sign in a case of manis that had shewn itself speedily after labour, as a guide to my prognosis respecting the probsbility of death, it would be the rapidity of the pulse." (Obstetric Medictine, third edition, pp. 561-62.) And Dr. Blunden, on the puerperal state generally, observes :- " I will not say the woman is always in danger when her pulse is above 100 , but when this is the case you ought alwuss to watch her; and, on the other hand, when the pulse is below 100 , when it is 95,90 , $\mathbf{8 6}$, or 80, in the minute, you may be sure she is safe; there is no one symp. tom which indicates disease or safety so neatly and olearly as the frequency of pulse." (Lectures on Midroifery.-Lancet, Sept. 27th, 1828, p. 803.)

Survly we shall do well to be on the look-out for hidden nocks, even in plowes where our best charts have thus most distinctly marked-deep water. + In two out of four fatal cases of peritonitis which I here attended, the milk, which had been suppreased, reappeared in the breasts a day or two beporperal diseasea. "The mill Hew all over har", is a common sajing with old nurees.

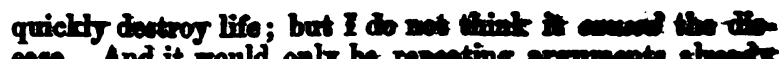
used, if I were to endeavour to show thint mpprecion of the used, if I were to endeavour to show that mpprecion of the
milk, when it takes place, is rathor an effect then s cares I think that mental disquietude in an excitable, hycterieal temperament, is generally alone in fanlt.

In seeking for an answer to the question I have proposed, I must say that I find nothing satisfactory in books, bo canse my own experience contradicts them; nor in my cases, because they contradict one another. It may, indeed, be suggested that my own bad management of the fatal caves may explain these seeming contradictions: I certainly feel that three deaths from manis out of a total of only 2,247 deliveries, the number on $\mathrm{my}$ midwifery register up to the present date, is an undue proportion, when Dr. Ramsbotham had only three such deaths out of a total of 48,996 deliveries. But on this point I must leave myself to the judg. ment of my peers. I have, at least, made a clean breast of it.

Alford, Lincolnshire, July 3, 1854 .

$$
\text { y }
$$

\section{ATMOSPHERIC PHENOMENA IN RELATION TO CHOLERA.}

By J. A. HINGESTON, Esq.

$$
\text { ro. IV.* }
$$

Durine the month of July, 26 cases of death from cholers were first reported, and subsequently 133 ; while the deaths from diarrhoea increased from 54 to 84 . The first 26 casen seem to have occurred chiefly about the 7 th, $8 \mathrm{th}, 9 \mathrm{th}, 12 \mathrm{th}$, and 15th of the month. The days preceding and accompanying these dates exhibited in a greater or less degree the state of atmospbere supposed to be connected with the prevalence of Asiatic cholera; that is to say, they were misty, orercast, damp, or wet, with a calm or light air, and the barometer at or about fair, but generally rather below it. At the beginning of the month, the mortality was as much as 203 above the average; but towards its close, at the exact time when the number of cholera cases was reported on the increase, the mortality fell to 108 below the average; by the end of the month it was "slightly in excess".

I have not drawn out tables of the weather, as heretofore, for the sake of brevity, but they shall be forthcoming if required, either entire or in part. It may be stated, that the temperature during the first part of July, was about foux degrees below the a verage; but that on the 18th, it rose above it, and continued to be so till the close of the month. The 24th was the hottest day on record since 1818 , when Fah. therm. stood at $79^{\circ}$. This year it ranged on the same day's date between $54^{\circ}$ and $84^{\circ}$ in the shade. On the 25th, it was $88^{\circ}$ in the shade; and, according to the reading at the Royal Observatory, Greenwich, $117 \cdot 6^{n}$ in the sun; I observed it here $110^{\circ}$ in the sun and $90^{\circ}$ in the shade at noon; which is said by Mr. Glaisher, of Lewisham, to be the hottest day on record since 1814. Both these days were cloudless, with sheet-lightning at night. For the most part, the nights throughout the month were chilly, although the days were warm and close.

Of the 133 fatal cases, "there were 42 under fifteen years of age, 78 men and women between that age and sixty Jears, and 13 persons sixty years old and upwards": so that it appears from the Registrar General's Return, the prin-
cipal mortality befell those in the middle of life. "Noxe than half the number of cases occurred on the south side of the river (Thames)-35 in the east districts, and the remainder in various other parts of the metropolis, as far as its western extremity." In 1849, not more than five fatal cases were reported in the first week of July in that year; although by the middle of August following, the deaths amounted to one in a 1,000 in London. Last yenr

- Former papers as follows:-1. Oct 21st, 1858; II. April 21at, 1864; III July 7 th, 1854 . 
Corimary mortatif was comiderably below the areage Troughont the month of July, but above it in the beginving of Angust.

That chaler is not confined to any particular localities, ling or low, terre firm or the ocean, is proved by its geographical history. It may have originated in the jungles of Jessore in Bengal; but we have heand of it in the snowy pasees of the Caucasus, along the sea-beach in various parts of the globe, in sandy deserts traversed by caravans, on boand-ship frequently, on alluvial plains, such as those on which Moscow stands, or in cities as elevated as that of Merico, the loftiest in the world; in the fiords of Norway and Scandinavia, upon the shallow Baltic, the deep German Sea, and the broad Atlantic. But whenever authentic accounts have reached us respecting the state of the atmoophere during its prevalence, they are uniformly the same. It would be exceedingly interesting, could we be placed in possession of accurate meteorological accounts from Marseilles, visited so fearfully at present by this pestilence.

The overcast sky during the prevalence of the disease has been, as far as my observations extend, of two kinds. One is that of thin cirro-strati, mackerel sky, as it is called, through which the sun shines with a pale watery light: these cirro-strati surround and follow the sun in his course. The second is that of dark smoky-looking cumuli, from N.W., moving up in a lowering manner. There is a calm, but no rain, all the while.

Connected with the approach of the epidemic, there is an adranced guard of indigestion, marked by a disrelish for food, a sense of precordial heat, and headache. It is best relieved by the neutral salts, conjoined with a bitter and the dilute sulphuric acid. This kind of indigestion, thus relieved, and the dark hue of the blood during the collapse, seem to point in the direction of Dr. Stevens' saline treatment. Subacute gastritis, heartburn, pain across the forehead, slight giddiness, offensive breath, and depraved urinary excretion (the urates, the phosphates, or at last suppression), indicating disturbed assimilation and sanguification, are (account for them as we please) not only the forerunning signs of the epidemic, but also those symptoms the most surely relieved by the neutral salts, a bitter, or the mineral acids. The question turns upon the therapeutics best suited for re-oxygenating the blood. Four articles of diet seem to be peculiarly obnoxious to the disease ; namely, eggs, fish, wine, and potatoes-the last in particular.

In putting forward these repeated observations in reference to cholera, I beg to say, that I have no favourite idea of my own that I am making a pet of. I shall only be too happy to be corrected, and to relinquish whatever I have adranced, the moment it can be shown to be erroneous and untenable.

Brighton, August 4th, 1854.

P.S. The subjoined extract is from a letter to the Editor of the Times, and published in the impression of that paper on August 3rd: it contains some sensible advice.

"With regard to the mode of aroiding cholera, a few suggestions may be available.

"I would recommend that lemon-juice should be taken at least once a-day, either alone or in a state of effervescence with potash or soda. Vegetables in a decomposed state, or meat with any taint, should be altogether eschewed; and hawkers of bad fruit, fish, or regetables, should have their articles condemned. Cabbages brought to London heaped up in carts are a fruitful source of disease; and potatoes already showing symptoms of disease should not be consumed.

" Exercise in the open country should be taken almost every day; and no one ought to remain in-doors twentyfour hours consecutively. The chlorides of zinc are much better disinfectants than the chlorides of lime, and personal ablution should be most freely used, together with constant chiange of linen. The defective act respecting baths and washhouses should at once be amended, and Government should devote a portion of revenue to the establishment of pablic bath and wahhouses in every arailable locality; they would nearly pay their orn expensen, if Government would lend a helping hand to erect them. Parishes aro too mean and short-sighted to go to the firet expense.

"I shall not trespass more on your valuable space. A hecatomb of victims will fall before much is done, I am well aware; but I am as convinced as that to-morrow's sun will set, that a house-to-house inspection of nuisances alone can remedy a crying evil, and alone meet the exigency of the present time.

"I remain yours very respectfully,

"Alfred Ebsworth, Surgeon.

“11, Trinity Street, Southwark."

\section{PERISCOPIC REVIEW.}

\section{SURGART.}

REPORT ON OPERATIVE SURGERY.

WE have not space at present to give in systematic order the surgical gleanings which we have made from cotemporary literature. In the mean time, the following paragraphs may interest our readers. The subjects referred to are :-

I. Excision of JoInts, and of Bones conNected wTth JoINTS; AND

ir. Operations iv Cases of Retention of Unine.

\section{I.-EXCISION OF JOINTS, AND OF BONES CONNECTED WITH JOINTS. EXCISION OF THE KNEE-JOINT.}

The successful case of excision of the knee jnint, recorded by Dr. Cortos in the last number of the Associatron Jotranax, (p. 696), gives fresh interest to the subject which it illustrates.

'To the successful cases of excision of the knee-joint must be added one which is related by Dr. Gundos Buck in the New York Medical Times for March 1854. An abstract is given in the American Journal of the Medical Sciences for April, 1854.

The patient had anchylosis of the knee, in consequence of a gunshot wound receivell on April 20 th, 1853 . On August 9th, the following operation was performed on him in the New York Hosnital :-

“A transverse incision was made from one condyle to the other, across the lower margin of the patella. A longitudinal incision intersected the middle of this, and extended four inches above and below it. After the flaps had been dissected up, the joint was opened by an incision across the ligamentum patellæ, and also across the lateral ligaments. The adhesions of the articular surfaces were hroken np by gradual forced flexion. A slice was then removed, with the common amputating saw, from the inferior surface of the condyles of the femur, including the pulley-like surface intervening between. Special care was taken to make this section on a plane parallel with the surfaces of support upon which the condyles rest, when the body is erect. The articular surface of the tibia was next removed on a level with the upper extremity of the fibula. These broad fresh-cut bony surfaces, which were very vascular and healthy, admitted of accurate coaptation without stretching the tendons and other parts in the ham. To secure them in close contact, a flexible iron wire was passed through both bones on each side, and the two ends twisted and left out between the flaps of the skin. The patella, being disorganised and softened, was remored, except the superior margin. The flaps of integument were brought together with sutures and adhesive straps, and the limb placed in a fracture-box. The constitutional fever was moderate, and disappeared within a fortnight. At the expiration of five and a half weeks, the wires, having become loose, were removed. No exfoliation was produced by their presence. At the end of nine weeks, the wound had entirely healed, and the patient could raise the limb from the bed. Slight motion between the bones was perceptible in the direction of flexion and extension, but none laterally. At the expiration of about three months, the patient was allowed to leave his bed, and use his crutches. On February 1st, 1854, he had been steadily improving up to the present time, and walked with a cane only. There was no mobility between the bones. The difference in length between the two limbs was one inch and a half, which permitted the foot to clear the surface of the ground without the body being thrown to the opposite side." 